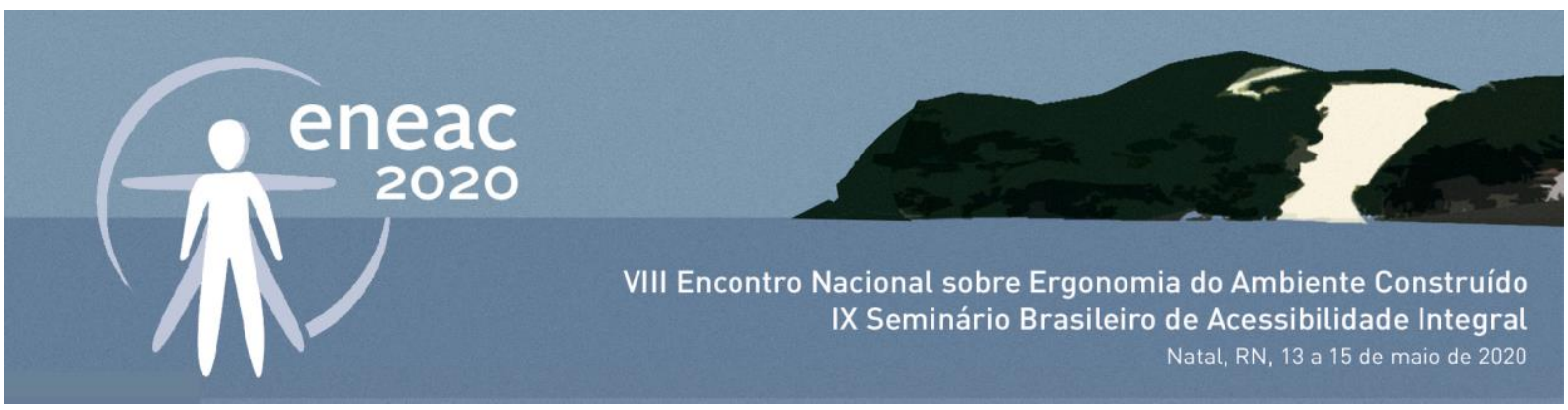

\title{
Análise ergonômica do ambiente construído: estudo de uma empresa startup em Fortaleza.
}

\author{
Ergonomic analysis of built environment: study of a startup company \\ in Fortaleza.
}

< LETÍCIA CAMPOS DIAS > Graduanda em Arquitetura e Urbanismo - UFC, leticiadias@arquitetura.ufc.br

$<$ VILMA VILLAROUCO >

Dra. em Engenharia, PPGDesign e PPErg-UFPE, PPGAUD-UFC, vvillarouco@gmail.com

< ZILSA MARIA PINTO SANTIAGO >

Doutora, PPGAUD-UFC, zilsa@arquitetura.ufc.br

\section{RESUMO.}

O estudo acerca da adequação do espaço construído de escritórios à realização das atividades que abrigam insere-se em um segmento da ergonomia que tem expandido sua visibilidade, na busca pela formatação de ambientes de trabalho confortáveis e produtivos. Nesse contexto, o presente artigo tem como finalidade apresentar o estudo realizado no escritório sede de uma empresa do tipo startup, localizado na cidade de Fortaleza, a partir da aplicação da Metodologia Ergonômica para o Ambiente Construído - MEAC, proposta por VILLAROUCO (2007), visando a obter um diagnóstico que forneça subsídios para elaboração do projeto de reforma e ambientação do espaço. Com os resultados obtidos, foi possível identificar os principais condicionantes ambientais, as interações entre as diversas variáveis do ambiente construído e as suas consequências para a percepção e o conforto dos usuários. Ao final, a elaboração de diretrizes projetuais a fim de alcançar o principal objetivo dos estudos da Ergonomia: garantir o conforto, bem-estar e segurança ao ser humano durante a realização das atividades inerentes à sua rotina.

PALAVRAS-CHAVE: análise ergonômica, ambiente construído, MEAC, escritório, corporativo.

\section{ABSTRACT}

The study about adequacy of the built space to carry out activities that it houses is a segment of Ergonomics that has it's visibility expanded on the last years, in order to organize comfortable and productive workspaces. In this context, this article aims to present a study realized in a startup company in Fortaleza, Brazil, applying the Ergonomic Methodology for the Built Environment - MEAC, proposed by VILLAROUCO (2007). The main objective was to obtain a diagnosis to guide the space's reform 


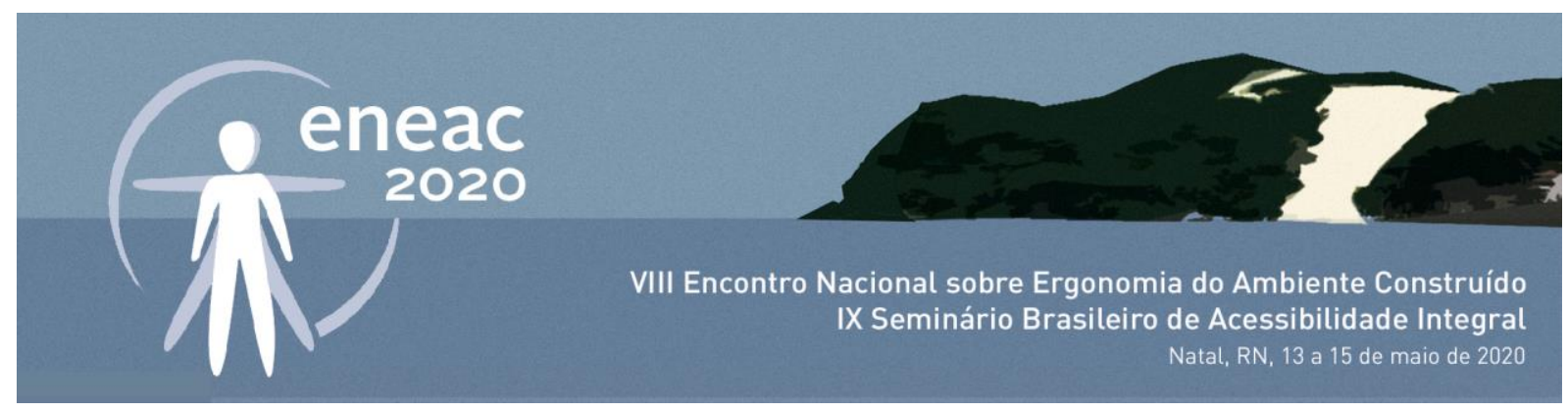

project. With the obtained results, it was possible to verify the environmental conditions, interactions between variables of built environment, and their consequences for user's perception and comfort. At the end, design guidelines were developed, in order to achieve the main objective of Ergonomics studies: guarantee the comfort, well-being and safety to the human being, specially during their performance on activities inherent to their work routines.

KEYWORDS: ergonomic analysis, built environment, MEAC, office, corporate.

\title{
1 INTRODUÇÃO
}

A compreensão da arquitetura corporativa e da sua evolução ao longo das décadas remonta ao entendimento dos fatores que influenciaram diretamente as suas transformações: o contexto político e socioeconômico, a atuação do mercado imobiliário, os avanços tecnológicos da construção civil e das telecomunicações, o crescimento das corporações e os modelos de gestão predominantes em cada momento. Sobre este processo, Vargas (2014) afirma que:

\footnotetext{
A compreensão da arquitetura e da produção de edifícios de escritórios conduz, imediatamente, aos principais elementos que conspiraram para o seu nascimento: a crescente demanda por terra urbana e a atuação do mercado imobiliário; a tecnologia da construção e das comunicações; o crescimento e a organização das corporações. Estes elementos, com intensidades e ênfases diferenciadas, interferiram significativamente na produção de edifícios de escritórios através do tempo, permitindo identificar alguns períodos característicos em âmbito internacional. (VARGAS, 2014)
}

O ambiente de trabalho como do século XXI é resultado de muitas transformações, evoluindo de abordagens rígidas e controladoras para um modelo mais humanizado, preocupado com o bem-estar das pessoas e assertivo no controle de resultados. Este fenômeno tem gerado mudanças na forma de produzir arquitetura corporativa: considerando que o bem-estar influencia a produtividade dos colaboradores, observou-se que seria uma estratégia de negócio investir na qualidade das interações dos usuários com o ambiente de trabalho, visando a estimular a convivência e proporcionar um ambiente físico e psicológico que seja confortável, seguro, agradável e, consequentemente, produtivo.

\begin{abstract}
Um dos princípios básicos para promover o bem-estar e, consequentemente, o aumento da produtividade dos usuários do espaço, é a preocupação com seu conforto. O fornecimento de produtos ajustáveis e sistemas que proporcionam ao indivíduo controle sobre seu espaço de trabalho são o segredo para o desenvolvimento de um ambiente ergonomicamente correto. (ADDI; LYTLE, 2000; HOK, 2016; SORRENTO, 2005 apud LINHARES; BARBOSA e TAKAMATSU, 2019)
\end{abstract}

Nessa direção, os conceitos e métodos da ergonomia aplicada aos ambientes construídos podem contribuir na consecução de espaços de trabalho mais confortáveis, melhor adequados às atividades que neles se desenvolvem e às características perceptuais daqueles que os utilizam. O presente estudo foi desenvolvido no intuito de analisar a qualidade do espaço físico de um escritório, tendo como objeto de estudo a sede de uma startup de e-commerce de produtos personalizados, localizada na cidade de Fortaleza, Ceará.

Miranda, Santos Jr e Dias (2016) citam a FINEP (2014) para definir uma startup como:

Uma empresa cuja estratégia empresarial e de negócios é sustentada pela inovação e cuja base técnica de produção está sujeita a mudanças frequentes, advindas da concorrência centrada em esforços continuados de pesquisa e desenvolvimento tecnológico. Principais características das empresas 


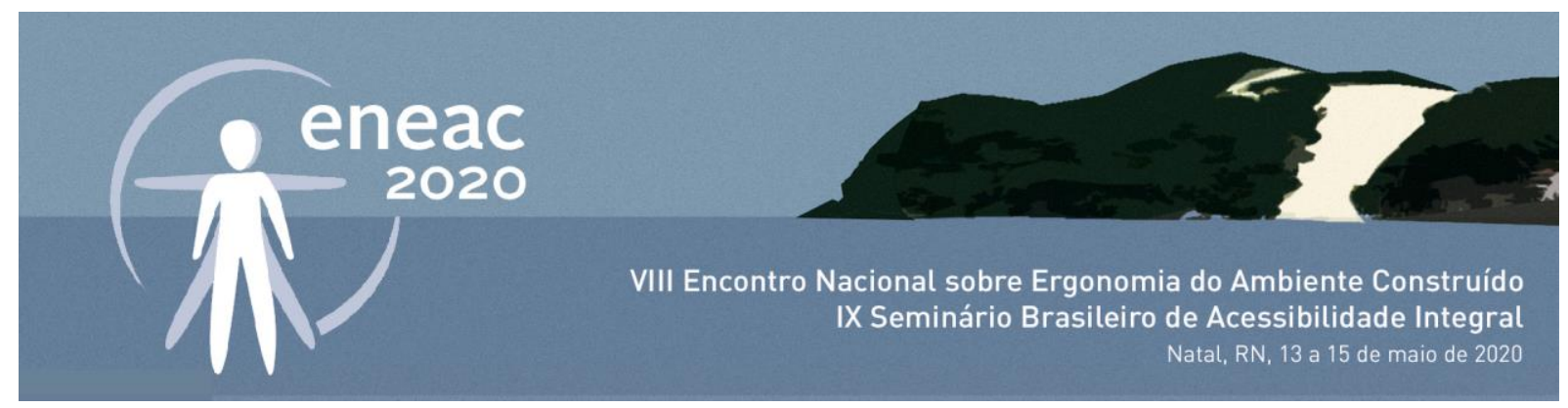

nascentes de base tecnológica: em estruturação empresarial (quase-empresa); sem posição definida no mercado; que buscam oportunidades em nichos de mercado com produtos/serviços inovadores e de alto valor agregado. (FINEP, 2014)

Ainda no sentido de entender uma startup, Linhares, Barbosa e Takamatsu (2019), apresentam a definição de Ries (2011), que afirma:

Startups são empresas que desenvolvem um serviço ou produto em um ambiente de extrema incerteza, ou seja, um mercado que lida com inovação, sem precedentes, e que, por esse motivo, não se tratam de empresas nas quais é adequado aplicar ferramentas tradicionais de planejamento. (RIES, 2011)

Inserido no cenário da startup, o estudo entende que, assim como é necessário utilizar ferramentas inovadoras de planejamento para o sucesso da empresa, também é necessária uma instalação física que favoreça as novas relações de trabalho. Pautado nestes argumentos tem como objetivo identificar as potencialidades e problemáticas do ambiente construído em relação aos seus usuários, como um diagnóstico para a elaboração de diretrizes e recomendações que colaborem para um projeto arquitetônico que promova a melhor qualidade e funcionamento do estabelecimento.

O objetivo delineado para o presente trabalho encontra eco em Linhares, Barbosa e Takamatsu (2019), quando colocam que

\footnotetext{
O design de interiores, por intermédio do planejamento da ocupação e do uso dos espaços - o que inclui os aspectos técnico práticos, estéticos e simbólicos dos ambientes-, tem o potencial de transmitir a identidade da empresa, agregar valor à marca e promover maior produtividade e conforto para os usuários do espaço. (LINHARES, BARBOSA E TAKAMATSU, 2019)
}

\section{METODOLOGIA}

A pesquisa teve como base a Metodologia Ergonômica para o Ambiente Construído - MEAC, proposta por Villarouco (2007). Essa metodologia consiste em uma abordagem que inclui e estabelece uma relação entre fatores físicos - dimensionamento, antropometria, iluminação, ventilação, ruídos, fluxos, deslocamentos, layouts, postos de trabalho, materiais de revestimento, cores, acessibilidade, segurança - e fatores psicológicos de percepção ambiental, observando como eles interagem entre si, para então compreender como o espaço físico pode influenciar o usuário, e como este último intervém no ambiente. Pode-se dizer, portanto, que se trata de uma pesquisa exploratória, qualitativa e descritiva que, por envolver muitos fatores, precisa se dividir em cinco etapas durante a usa execução. São estas:

\section{Etapa 1 - Análise Global do Ambiente}

Etapa de reconhecer o ambiente e coletar as informações iniciais, através de walkthrough, entrevistas iniciais e registros fotográficos. $O$ objetivo da primeira fase é entender a relação ambiente-usuário-atividade e identificar problemas que indiquem a demanda por uma intervenção ergonômica.

\section{Etapa 2 - Identificação da Configuração Ambiental}

Neste segundo momento, realiza-se um levantamento físico mais aprofundado do ambiente, medindo não somente o dimensionamento do espaço, mas também seus níveis de iluminação, ruído 


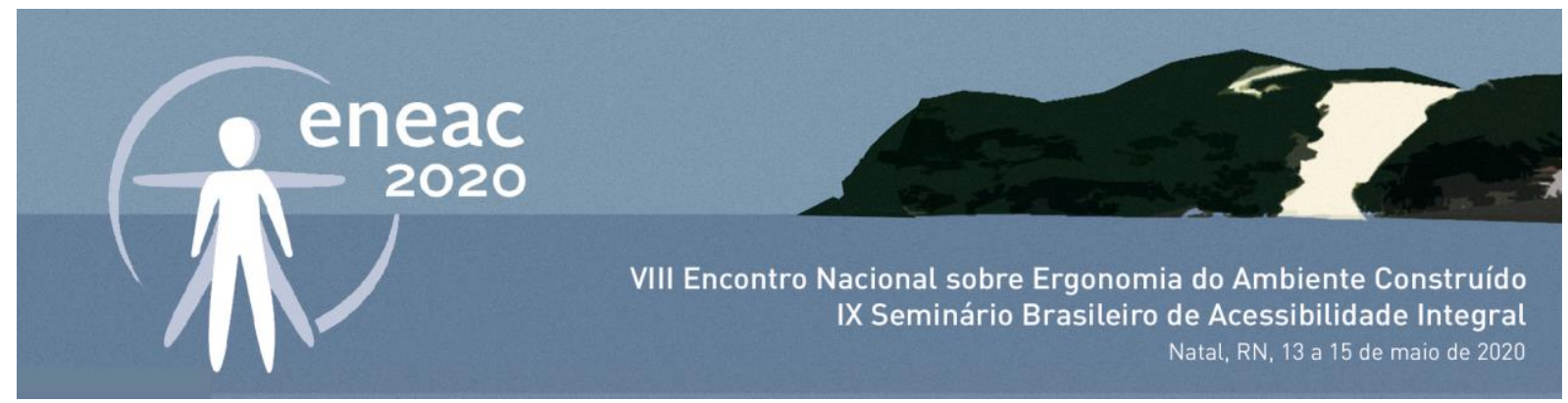

e ventilação; além disso, mapeia layout, fluxos e deslocamentos realizados dentro do espaço, e por fim registra observações a respeito dos postos de trabalho, materiais de revestimento, cores, e condições de segurança e acessibilidade. Com o levantamento em mãos, é possível fazer as primeiras hipóteses sobre a influência das condições do espaço físico para as atividades que ali acontecem.

\section{Etapa 3 - Avaliação do ambiente em uso}

Estando a par de todas as características físicas do ambiente, o pesquisador passa a fazer observações sobre o ambiente em uso, e descrever, segundo a sua percepção, de que forma o espaço auxilia ou atrapalha as atividades que ali acontecem.

\section{Etapa 4 - Percepção ambiental dos usuários}

Nesta última etapa de levantamento de informações, o pesquisador se utiliza de ferramentas da psicologia ambiental para buscar entender as percepções que os usuários têm sobre o seu ambiente.

\section{Etapa 5 - Diagnóstico ergonômico do ambiente e recomendações}

o diagnóstico é feito após a junção e análise de todos os dados levantados, e resume a situação do estabelecimento e os problemas nele identificados, permitindo a proposição de mudanças para corrigi-los.

\section{APLICAÇÃO DA METODOLOGIA}

O estudo foi realizado no escritório de uma startup localizada na Aldeota, bairro situado em zona nobre da cidade de Fortaleza, Ceará. A empresa foi fundada no ano de 2015, atuando inicialmente como um e-commerce de acessórios personalizados para celular, e expandiu sua cartela de produtos para a área têxtil, incluindo outros produtos customizados, segundo o propósito de conectar pessoas através de seus produtos. Possui um caráter descontraído e criativo que se reflete nas pessoas que a compõem e na sua organização interna. A coleta de dados foi realizada durante visitas ao escritório selecionado, através de entrevistas, medições e observações.

\section{Etapa 1 - Análise Global do Ambiente}

O escritório está instalado em uma casa que passou por reformas e adaptações, onde outros estabelecimentos comerciais já funcionaram antes da sua chegada. Trata-se de uma edificação térrea, de aproximadamente $900 \mathrm{~m}^{2}$ de área (Figura 01), e possui um estacionamento com 8 vagas. Funciona de segunda a sexta, em horários flexíveis, que podem variar das 08:00h às 17:00h ou das 9:00 às 18:00, de acordo com a preferência de cada funcionário ou setor. 0 quadro de colaboradores, na data da visita, era composto por 68 pessoas. 


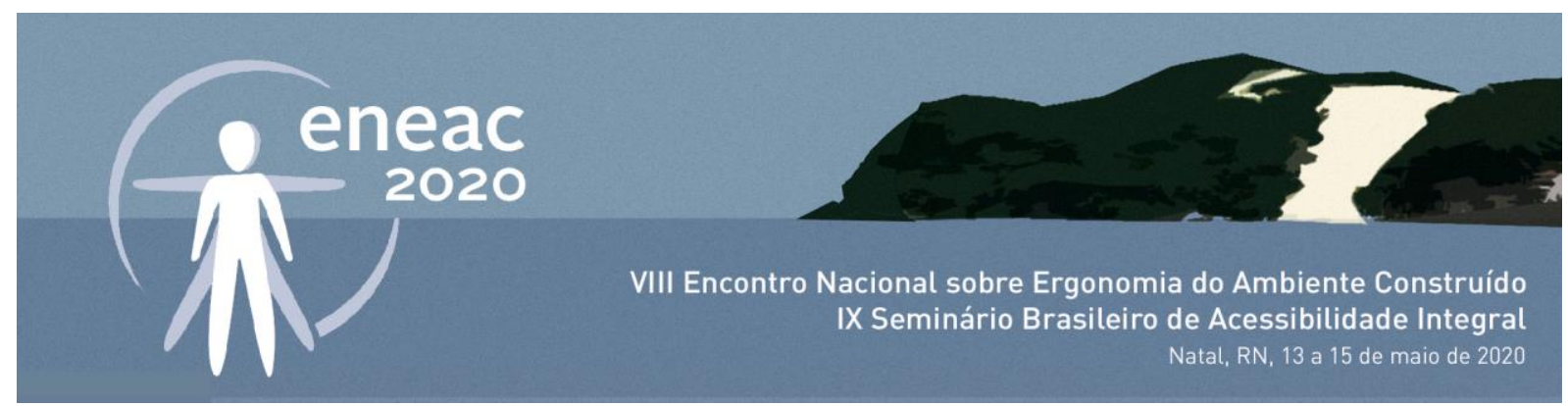

Figura 1: Planta baixa da edificação

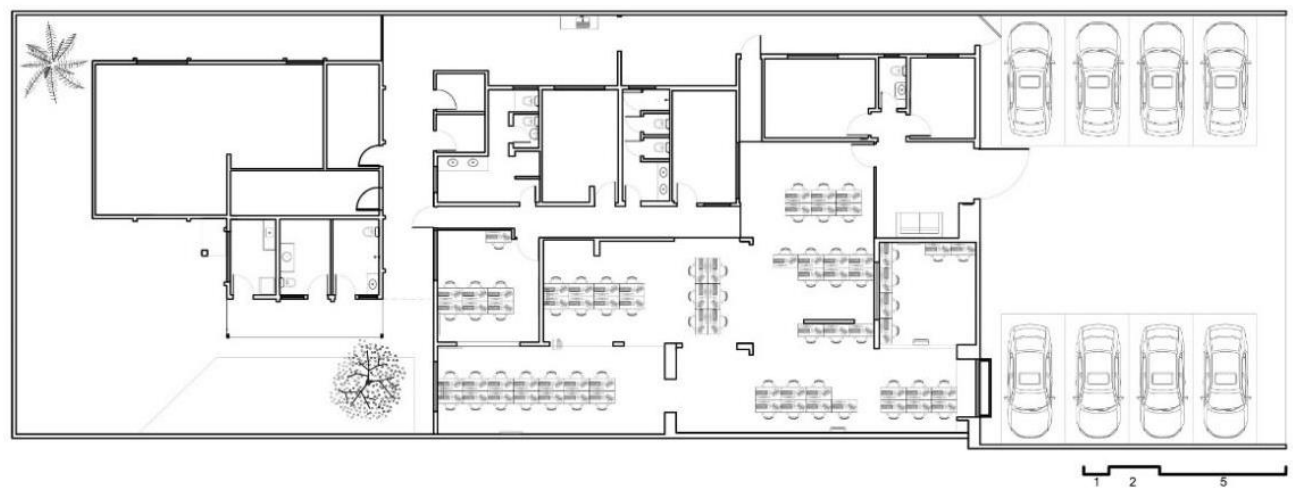

Fonte: produzido pelas autoras, 2019.

Todos os funcionários trabalham reunidos no mesmo ambiente, aqui denominado sala técnica (figura 2), e o diagnóstico se concentrou apenas neste espaço, cuja área é de aproximadamente $180 \mathrm{~m}^{2}$, organizada em um arranjo físico composto por 70 mesas e cadeiras destinadas aos funcionários, agrupadas em dez ilhas de acordo com os setores da empresa, além de armários, impressoras e televisores.

A percepção inicial foi de um ambiente muito descontraído e com intervenções criativas que revelam um cuidado por parte dos gestores com a qualidade do espaço (figura 3). No entanto, à primeira vista já é possível perceber que as dimensões da sala não comportam a quantidade de funcionários que ali trabalham, e que o fato de não haver compartimentação acarreta em problemas como excesso de ruídos e desorganização da sala, prejudicando a concentração dos usuários.

Essa organização espacial gerou uma demanda muito específica da empresa de criar um espaço denominado sala do foco, uma pequena sala usada pelos funcionários quando precisam ficar sozinhos para se concentrar. O edifício se distribui nos seguintes ambientes: recepção, sala técnica, quatro salas de reunião, sala do foco/ biblioteca, sala de produção de conteúdo, áreas de serviço como copa e banheiros, e uma área externa reservada para convivência. Também pretendem criar uma sala para realização de vídeo chamadas, uma vez que muitas de suas reuniões acontecem à distância.

Figura 2: Planta baixa da edificação com sala técnica em destaque

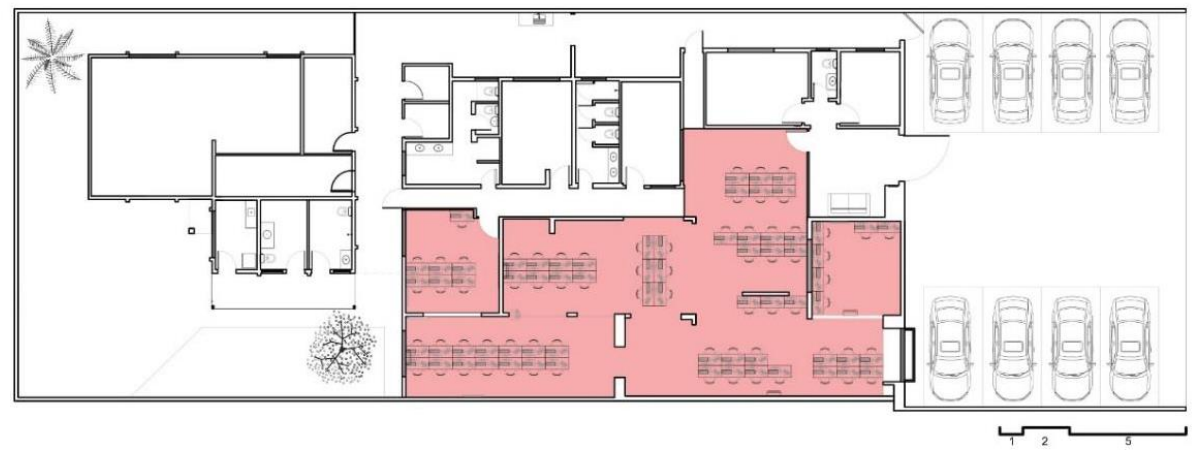

Fonte: produzido pelas autoras, 2019. 


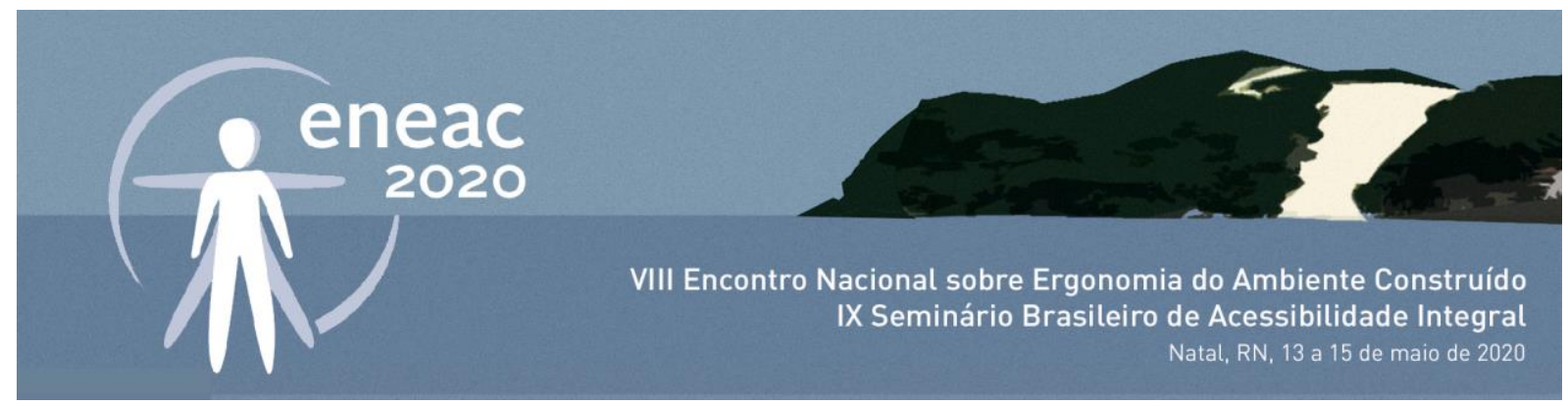

\section{Etapa 2 - Identificação da configuração ambiental}

\section{Ambiente lumínico}

Iluminação artificial, na cor branco frio, composta por 13 luminárias de lâmpadas tubulares e 6 de embutir no forro, totalizando 19 luminárias. Observando a olho nu, a iluminação é suficiente e regular, exceto por uma região onde a luz é azulada e insuficiente. Existem três janelas no ambiente, e todas são fechadas por cortinas que não permitem a entrada de luz natural.

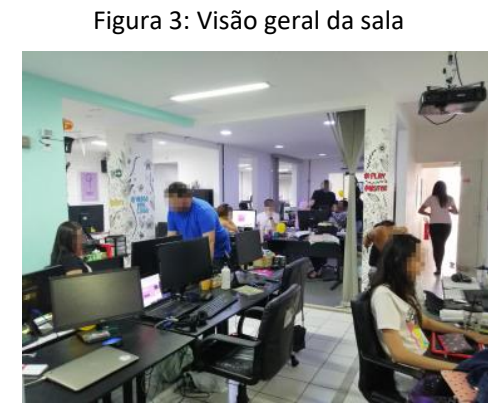

Fonte: acervo das autoras, 2019
Figura 4: Visão geral da iluminação

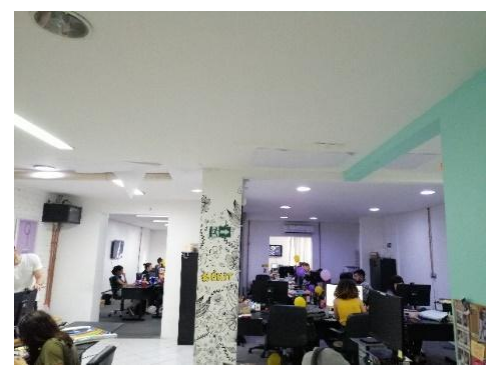

Fonte: acervo das autoras, 2019

No diagnóstico, foi realizada uma medição dos níveis de iluminação utilizando um luxímetro nos pontos indicados na figura 5. As medições foram realizadas no plano de trabalho das mesas, os pontos escolhidos foram distribuídos de modo a compreender toda a área da sala. Os pontos $\mathrm{B}$ e $\mathrm{C}$ estavam localizados na sala com iluminação azulada, onde se verificou níveis mais baixos de luminância, e o ponto $L$, localizado próximo a uma parede negra e distante de qualquer fonte de iluminação, foi o ponto com menor iluminação de todo o ambiente.

Figura 5: Distribuição das lâmpadas pelo ambiente.

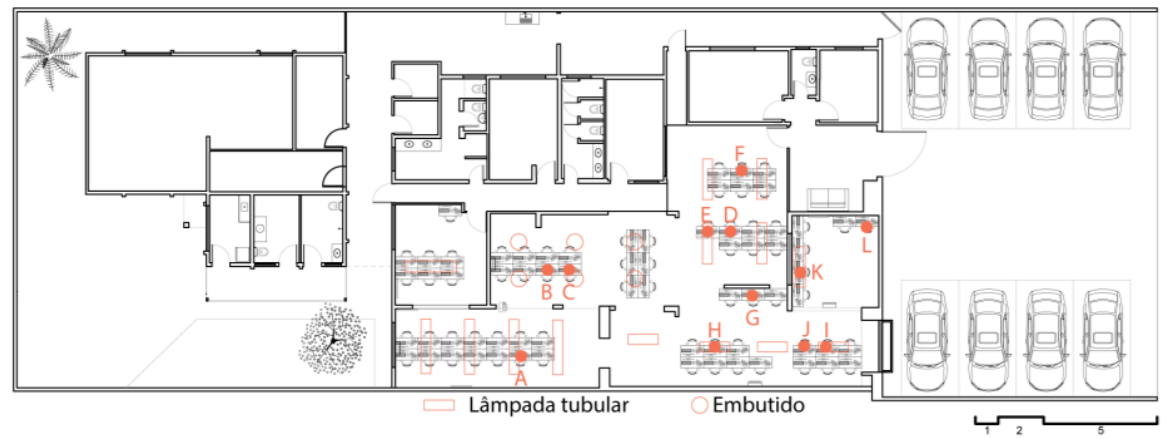

Fonte: produzido pelas autoras, 2019.

A tabela 1 compila os valores aferidos, comparando-os à Norma de Higiene Ocupacional no11 (NHO 11) da Fundacentro, a qual estabelece um nível de iluminamento mínimo de 500 lux para ambientes de escritório, e é adotada pela NR17 para os níveis de iluminância mínimos em ambientes internos. Analisando a tabela, percebe-se que nenhum dos valores aferidos está de acordo com a norma. 


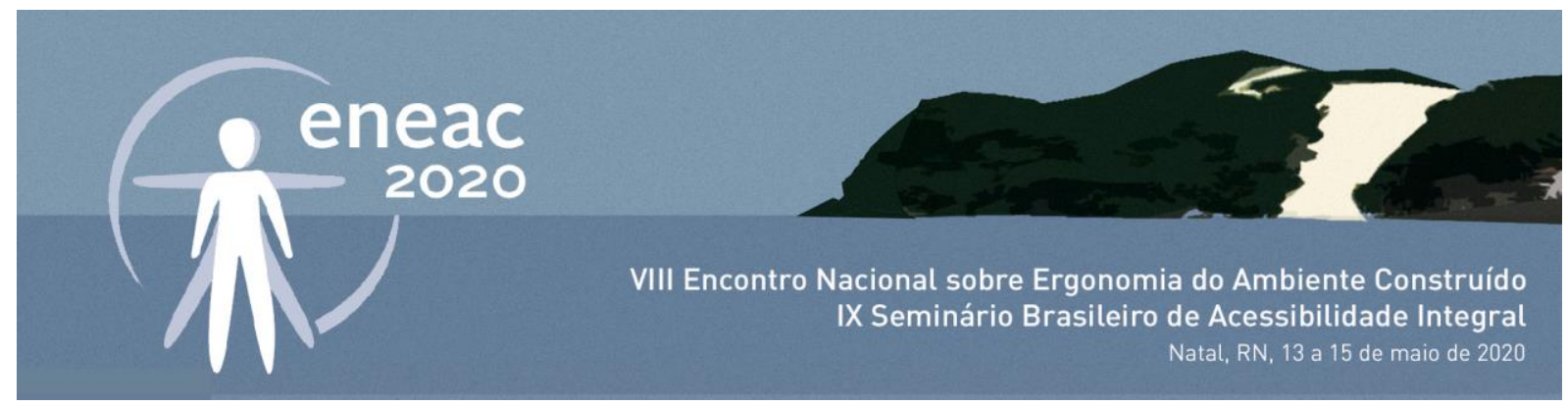

Tabela 1: níveis de iluminação registrados no luxímetro

\begin{tabular}{c|c} 
Local & Valor (lux) \\
\hline A & 235.0 \\
\hline B & 49.0 \\
\hline C & 79.0 \\
\hline D & 167.0 \\
\hline E & 189.2 \\
\hline F & 150.0 \\
\hline G & 40.0 \\
\hline H & 292.0 \\
\hline I & 348.0 \\
\hline J & 220.0 \\
\hline K & 330.0 \\
\hline L & 34.0
\end{tabular}

\section{Ambiente acústico}

Por se tratar de um ambiente ocupado por em média 60 pessoas simultaneamente, o alto nível de ruído é um problema que incomoda os usuários do espaço. Em muitos postos de trabalho foi observada a presença de fones de ouvido, que são usados pelos mesmos para se isolar do ruído do ambiente e manter a concentração necessária para trabalhar.

Com o auxílio de um decibelímetro foram medidos os decibels em dois pontos da sala, na altura da zona auditiva de uma pessoa. Em cada um dos dois pontos escolhidos, foram feitas 10 gravações de 10 segundos, em que ao final de cada gravação o equipamento informava os níveis de ruído máximo e mínimo registrados durante aquele intervalo. Portanto, para cada um dos pontos, foi possível tirar uma média aritmética das 10 máximas e das 10 mínimas, aproximando-se assim do nível médio de ruído em cada ponto, conforme a tabela 02 .

Tabela 2: níveis de ruído registrados no decibelímetro

\begin{tabular}{c|c|c|c}
\multicolumn{2}{c}{ Ponto A } & \multicolumn{2}{c}{ Ponto B } \\
\hline Máximo & Mínimo & Máximo & Mínimo \\
\hline 69.2 & 57.6 & 67.2 & 57.7 \\
\hline 72.1 & 58.8 & 69.3 & 59.0 \\
\hline 65.2 & 54.1 & 70.3 & 61.7 \\
\hline 71.1 & 56.7 & 71.1 & 56.0 \\
\hline 63.9 & 55.7 & 63.6 & 57.6 \\
\hline 70 & 59.2 & 66.1 & 58.8 \\
\hline 70.4 & 57.7 & 62.8 & 55.3 \\
\hline 70.4 & 58.1 & 63.1 & 56.0 \\
\hline 71.4 & 53.8 & 64.6 & 56.0 \\
\hline 71.3 & 57.3 & 62.6 & 56.3 \\
\hline Média: & Média: & Média: & Média: \\
$70 \mathrm{~dB}$ & $56.9 \mathrm{~dB}$ & $66.07 \mathrm{~dB}$ & $57.44 \mathrm{~dB}$ \\
\hline \multicolumn{3}{c}{ Média final: $63.45 \mathrm{~dB}$} & Média final: $61.75 \mathrm{~dB}$ \\
\hline \multicolumn{4}{c}{}
\end{tabular}




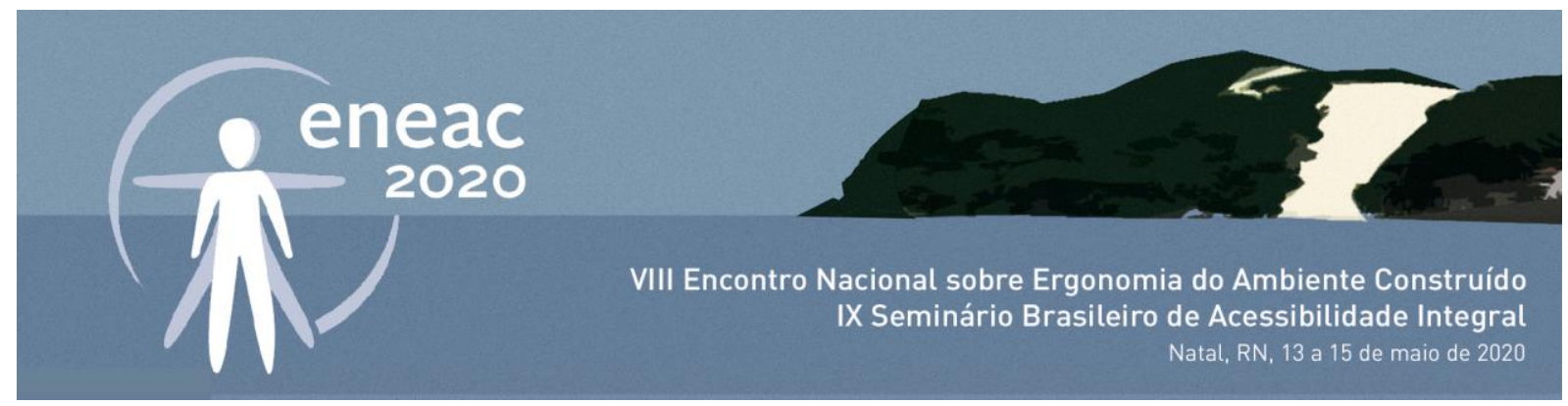

Observando a tabela e comparando-a com os parâmetros da ABNT NBR 10152, que trata dos níveis de ruído para o conforto acústico, é possível perceber que as médias estão próximas ao limite de 65 $\mathrm{dB}$ estipulados pela norma, e que os valores encontrados pelo decibelímetro ultrapassaram esse limite em diversos momentos.

\section{Ambiente térmico}

Linhares, Barbosa e Takamatsu (2019) citam Hok (2016) para afirmar que:

O conforto termal é obtido por meio da combinação harmoniosa entre fluxo de ar, umidade e temperatura, e que, a partir do momento que o controle desses fatores é proporcionado aos usuários do espaço, há o aumento da produtividade por parte dos mesmos. (HOK, 2016)

No objeto de estudo, o ambiente é fechado e climatizado, não utiliza suas aberturas para ventilação natural, pois as janelas ficam sempre fechadas. Possui 5 aparelhos de ar condicionado split.

Com o intuito de averiguar os valores médios de temperatura, umidade e velocidade do ar, foram realizadas medições usando um termômetro e um anemômetro nos pontos ilustrados na figura 6 .

Figura 6: pontos de medição da temperatura, umidade e velocidade do ar no interior da sala.

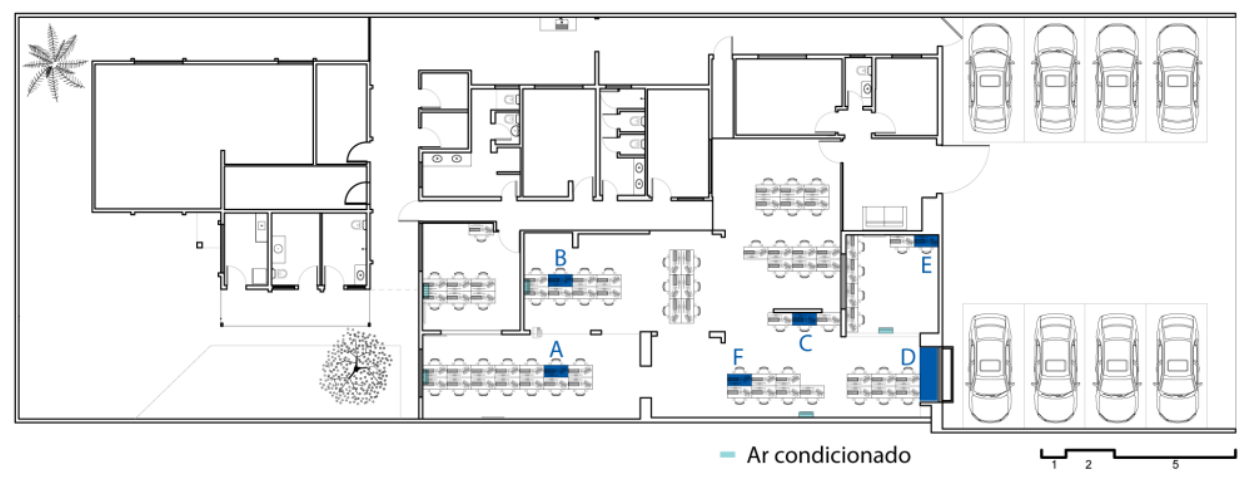

Fonte: produzido pelas autoras, 2019.

Foram selecionados 6 pontos de medição, utilizando como critério a sua posição em relação a elementos que afetavam diretamente a temperatura, como os aparelhos de ar condicionado e as janelas. Nos pontos A, B e C foi medida a velocidade do ar, visto que esses postos de trabalho estão localizados imediatamente em frente aos aparelhos de ar condicionado e ali o ar circula com maior velocidade. Os postos de trabalho localizados nesses pontos sempre tinham agasalhos nas cadeiras, indicando que essa temperatura baixa deixa os usuários em desconforto.

Tabela 3: pontos de medição da temperatura, umidade e velocidade do ar dentro da sala.

\begin{tabular}{|c|c|c|c|c|}
\hline \multirow[t]{2}{*}{ Local } & \multirow{2}{*}{$\begin{array}{c}\text { Temperatura } \\
(\stackrel{\circ}{ } \text { C) }\end{array}$} & \multirow{2}{*}{$\begin{array}{c}\text { Umidade do } \\
\text { ar }\end{array}$} & \multicolumn{2}{|c|}{ Velocidade do $\operatorname{ar}(\mathrm{m} / \mathrm{s})$} \\
\hline & & & Máxima & Mínima \\
\hline A & $23.4^{\circ} \mathrm{C}$ & $62 \%$ & 0.89 & 0.22 \\
\hline$B$ & $22.8^{\circ} \mathrm{C}$ & $63 \%$ & 0.44 & 0.04 \\
\hline$C$ & $23.8^{\circ} \mathrm{C}$ & $63 \%$ & 0.84 & - \\
\hline $\mathrm{D}$ & $25.2^{\circ} \mathrm{C}$ & $59 \%$ & - & - \\
\hline$E$ & $25.4^{\circ} \mathrm{C}$ & $58 \%$ & - & - \\
\hline $\mathrm{F}$ & $24.5^{\circ} \mathrm{C}$ & $61 \%$ & - & - \\
\hline
\end{tabular}




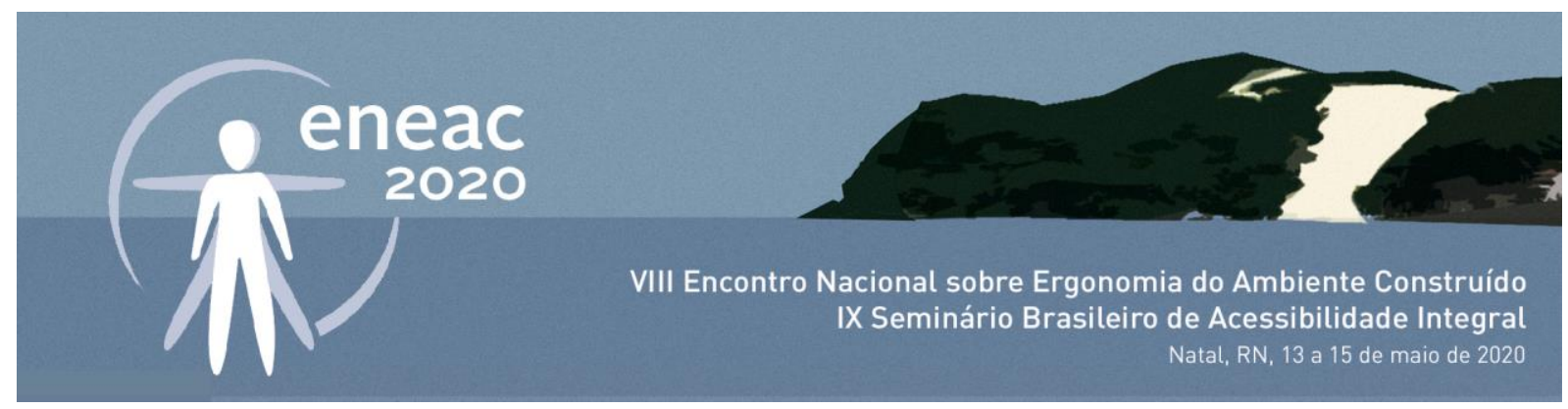

Apesar do conforto térmico depender do indivíduo e cada um ter preferências climáticas próprias, a NR17 estabelece como confortável o índice de temperatura efetiva entre $20^{\circ} \mathrm{C}$ e $23^{\circ} \mathrm{C}$ e umidade relativa mínima de $40 \%$. Os dados obtidos sobre a umidade relativa do ar atendem as exigências normativas, enquanto a temperatura de alguns pontos está acima do valor estabelecido. Os pontos A, B e C, localizados em frente aos aparelhos de ar condicionado, registraram temperaturas mais frias, enquanto o ponto $D$, próximo da janela, registrou a maior temperatura da sala, em uma variação significativa de $1.6 \circ \mathrm{C}$.

\section{Acessibilidade}

É perceptível a olho nu que o estabelecimento está em desacordo com a norma de acessibilidade desde o acesso, devido a um degrau na porta da recepção. No interior da sala técnica, também existem pequenos desníveis, e não há presença de rampas em nenhum local. Considerando-se o módulo de referência para acessibilidade (figura 7) estabelecido pela ABNT NBR 9050-2015, as circulações são estreitas. Ademais, não existe sinalização podotátil, assim como não existem banheiros acessíveis.

Existem dois banheiros (figura 8) cujas dimensões atendem aos requisitos da Norma de Acessibilidade, a ABNT-NBR 9050, no entanto não possuem barras de apoio, revestimentos adequados, porta com abertura externa, sinalização e nem sequer rota acessível para chegar até eles. Apesar de não serem acessíveis, com algumas intervenções simples poderiam vir a se tornar.

Figura 7: Módulo de acessibilidade para cadeirantes

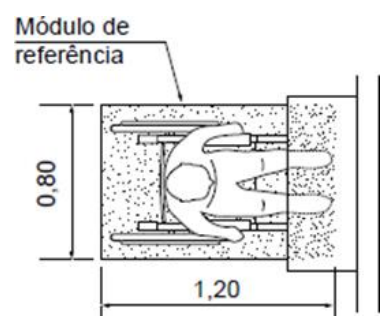

Fonte: ABNT NBR 9050
Figura 8: Banheiro com dimensões acessíveis

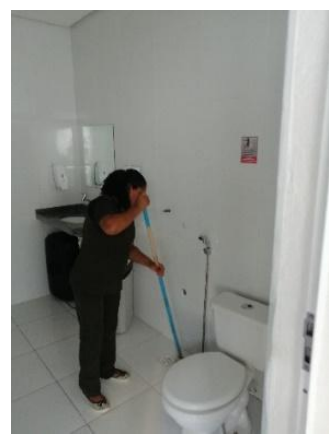

Fonte: acervo das autoras, 2019
Figura 9: imagem da empresa

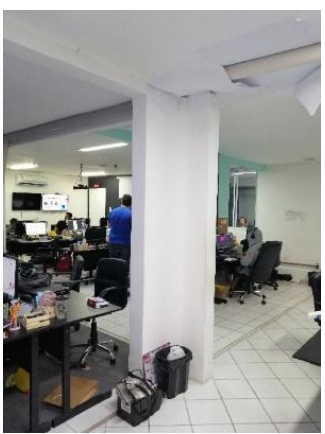

Fonte: acervo das autoras, 2019

\section{Materiais de revestimento}

A materialidade do ambiente é composta por piso em cerâmica $30 \times 30 \mathrm{~cm}$ e carpete em alguns espaços; teto com forro de gesso pintado com tinta PVA látex branca, apresentando falhas e rasgos fechados de maneira improvisada com cartolina branca; paredes também predominantemente pintadas em tinta branca, exceto por alguns painéis artísticos e uma parede revestida de tijolinhos brancos; mobiliário predominantemente em MDF. A estética do ambiente é bastante neutra, conforme ilustra a figura 9 , com predomínio do branco e presença de alguns pontos de cor nas paredes. 


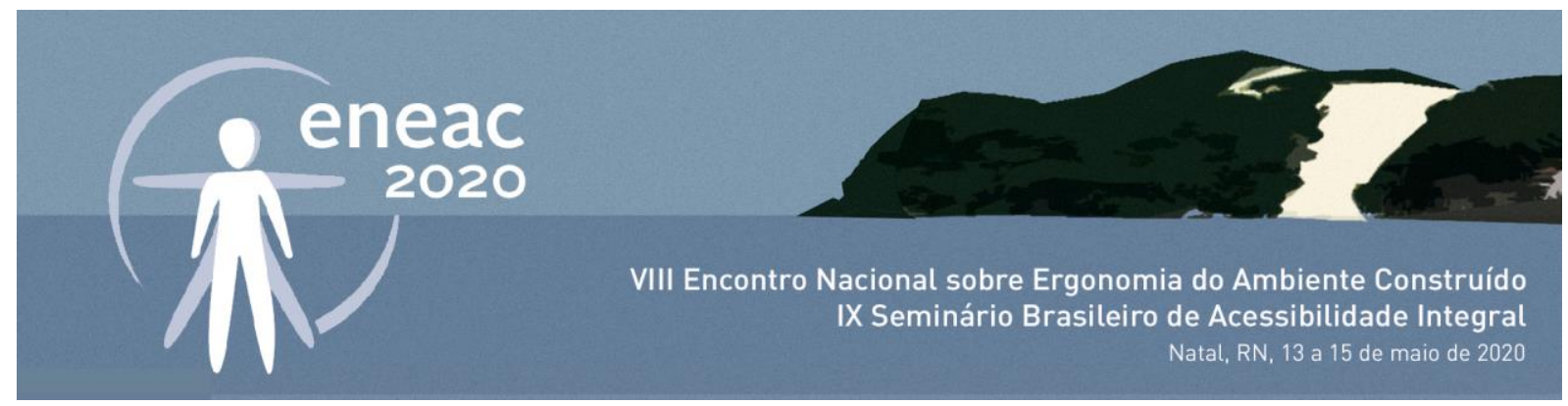

\section{Segurança}

O ambiente apresenta risco de acidentes causados pelas suas instalações elétricas, devido aos diversos fios espalhados no chão e embaixo das mesas. Há também risco de quedas devido aos desníveis que existem no ambiente. 0 excesso de móveis, produtos e caixas espalhadas pelo chão também dificulta a rota de fuga em casos de incêndio e sinistro.

\section{Etapa 3 - Avaliação do ambiente em uso}

\section{Fluxos e deslocamentos}

Para analisar os principais fluxos e deslocamentos realizados no interior da sala, considerando seu arranjo espacial, foram utilizados modelos antropométricos (figura 10) que permitem a avaliação da qualidade dessas circulações, em uma sobreposição dos modelos sobre a planta de layout do ambiente (figura 11), em escalas de proporções reais, feito com auxílio do software AutoCAD. Os modelos antropométricos escolhidos são baseados nas medidas adultas masculinas sugeridas por Panero e Zelnik (2008), e são distribuídos em cores que simbolizam o nível de inadequação da circulação, onde a cor verde representa circulações adequadas, o amarelo representa circulações que necessitam de atenção, e o vermelho, circulações de risco (figura 12). O critério adotado para classificar a circulação foi a presença de obstáculos invadindo a área de proteção dos modelos antropométricos.

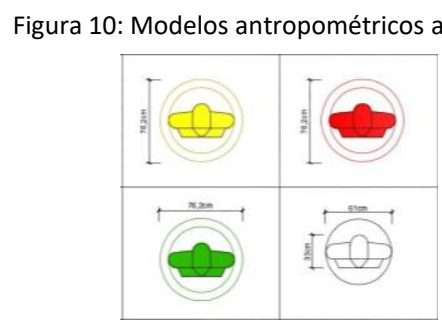

Fonte: produzido pelas autoras, 2019

Figura 11: planta baixa com fluxos e deslocamentos

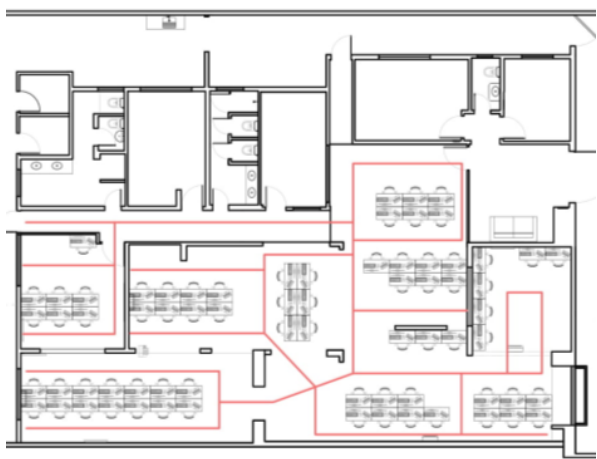

Fonte: produzido pelas autoras, 2019
Figura 12: simulação das circulações horizontais

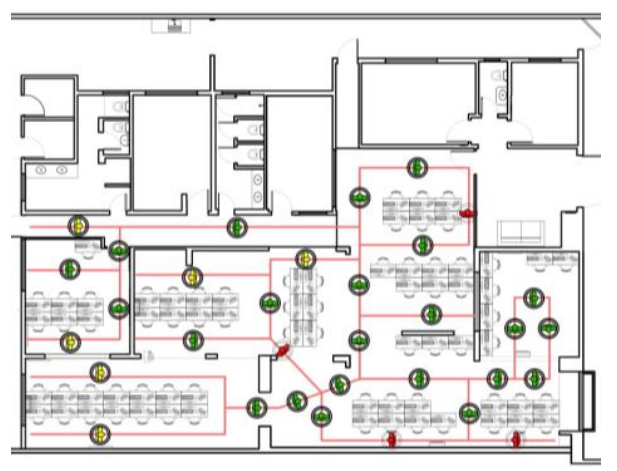

Fonte: produzido pelas autoras, 2019 


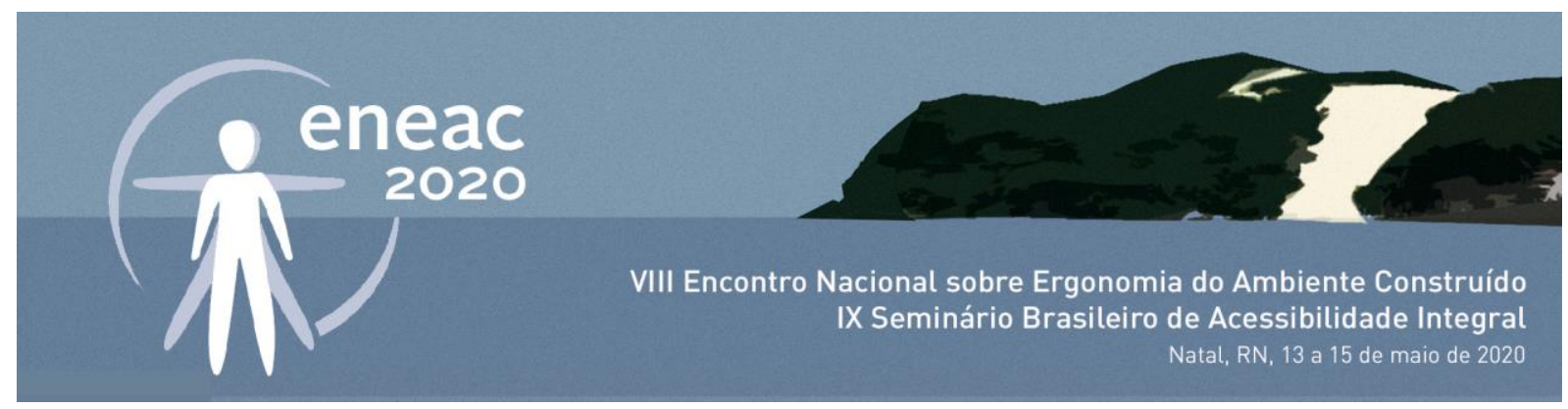

A partir da análise da planta, verifica-se que circulações adequadas predominam em $71.9 \%$ do ambiente, encontrando-se situações de risco em apenas 9.4\%, enquanto $18.8 \%$ merecem atenção. No entanto, todas as circulações passam a ser arriscadas devido a outros fatores além do layout, como os desníveis e os objetos espalhados pelo chão, resultantes da falta de espaço para acomodálos. Outro ponto observado é a grande quantidade de circulações sem saída, corredores onde a pessoa deve entrar e sair passando pelo mesmo local, situação que causa esbarros entre pessoas andando em sentidos opostos.

\section{Etapa 4 - Percepção ambiental dos usuários}

Ao final das três etapas iniciais, onde foram registradas as observações do ponto de vista do pesquisador, inicia-se o momento de estudar as percepções dos usuários do espaço através de uma ferramenta da Psicologia Ambiental, denominada Constelação de Atributos (EKAMBI-SCHMIDT, 1974) a qual gera modelos gráficos que permitem identificar e qualificar atributos ligados à percepção do ambiente. $O$ método prevê duas perguntas fundamentais, a primeira acerca do espaço imaginário(subjetivo), e outra para o espaço real (objetivo), e as respostas são compiladas agrupando significados e afinidades geradas. Com o auxílio de um formulário online, foram obtidas 40 respostas para as seguintes perguntas: "quando pensa em um ambiente de escritório, quais imagens vêm à sua mente?" e "quando pensa no escritório em que trabalha, quais imagens vêm à sua mente?"

Os gráficos ilustram a "distância psicológica" dos atributos, relacionando-os à percepção de conforto dos usuários, isto é: quanto mais perto um atributo está do centro, mais vezes foi mencionado pelos entrevistados, indicando que está mais presente nas suas percepções. A figura 12 revela que os funcionários percebem o seu ambiente de trabalho como um local agradável, pelo seu clima organizacional, porém desconfortável devido a características físicas, como a desorganização e o excesso de ruído. Comparando com o gráfico 13, elaborado para um ambiente de escritório imaginário, percebe-se que foram mencionadas principalmente características como organização, conforto e mobiliário ergonômico, que correspondem às maiores dores do espaço real, o que significa que os usuários se lembraram primeiro daquilo que lhes faz falta.

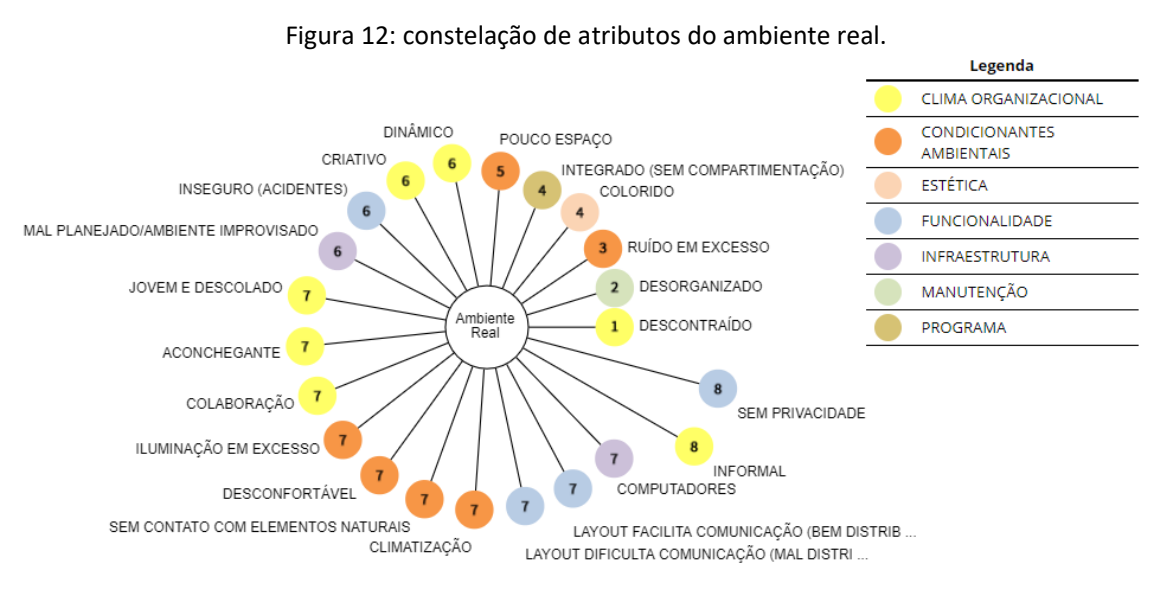

Fonte: produzido pelas autoras, 2019. 

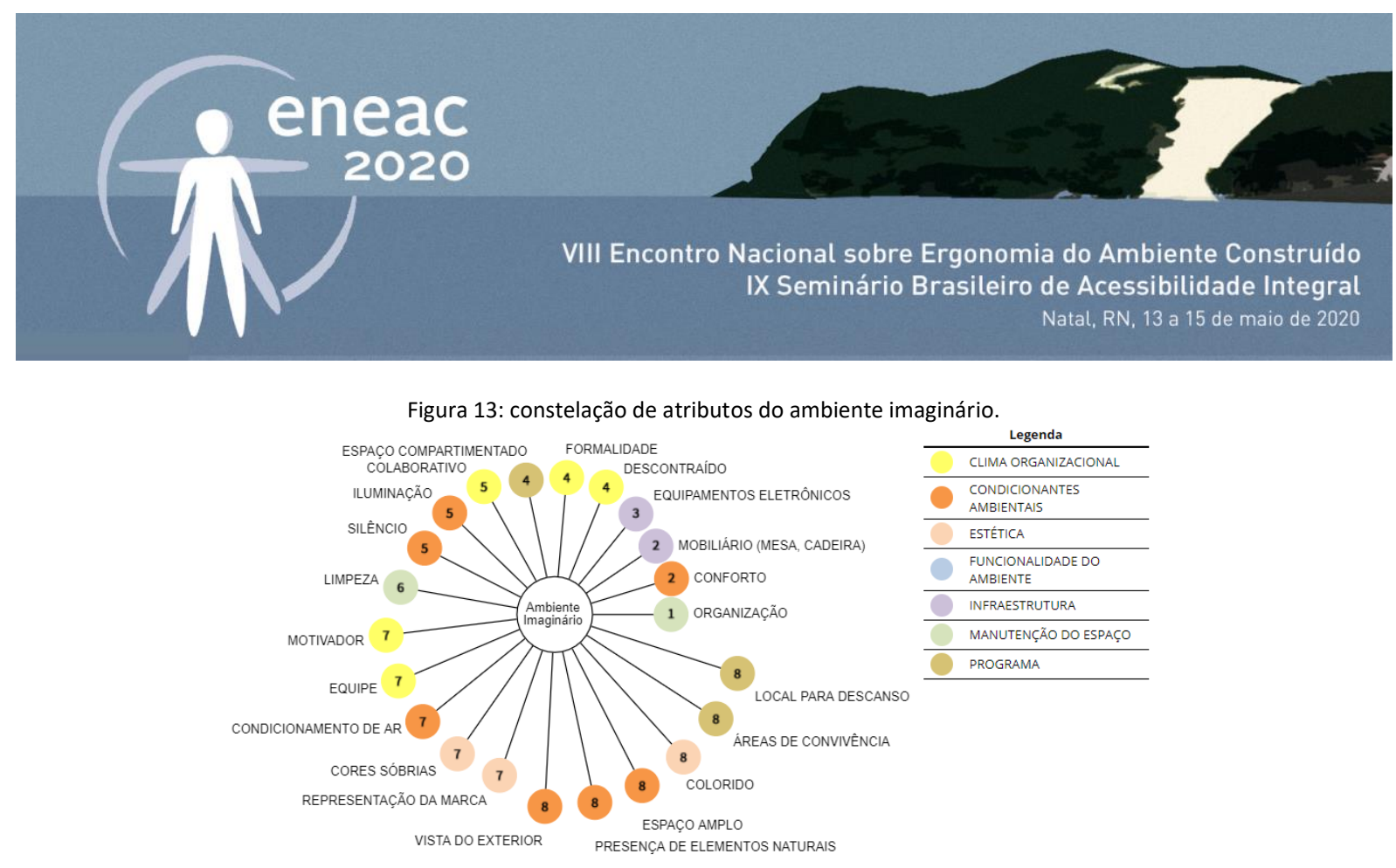

Fonte: produzido pelas autoras, 2019.

Convém ainda esclarecer que nesta etapa de entendimento da percepção do usuário pode ser adotada qualquer ferramenta que se destine a esta finalidade. A Constelação de Atributos é apenas uma das possibilidades, mas que não se adequa a caso cuja amostra tenha poucas pessoas.

\section{Etapa 5 - Diagnóstico ergonômico do ambiente e recomendações}

\section{Diagnóstico ergonômico}

Após o levantamento de todas as informações necessárias, o diagnóstico comprova que o ambiente não oferece as condições ideais de trabalho e produtividade para os funcionários da empresa. Não comporta a quantidade de pessoas que abriga nem em suas dimensões, nem em suas condições acústicas que são inadequadas para o número de indivíduos reunidos no ambiente.

A iluminação, considerada insuficiente pelas normas vigentes, é considerada excessiva pelos funcionários, os quais trabalham em computadores durante todo o expediente. Essa discrepância indica que, na verdade, não se trata do nível de luminância, mas do tipo de iluminação, que está inadequado e na cor errada, causando ofuscamentos e cansaço visual.

A temperatura não é igualmente distribuída por toda a sala, deixando alguns pontos mais quentes e outros mais frios, e o posicionamento dos aparelhos de ar condicionado incomoda alguns postos de trabalho.

A falta de espaço resulta no uso de mobiliários inadequados, que não comportam todos os pertences dos funcionários, e estes acabam ficando espalhados no piso e nas mesas, causando sensação de desorganização e risco de acidentes nas circulações.

Esteticamente, a arquitetura não reflete a personalidade da marca e nem dos seus colaboradores, e mesmo com algumas intervenções criativas no espaço, a sua desorganização polui visualmente e impede a apreensão da identidade do espaço. 


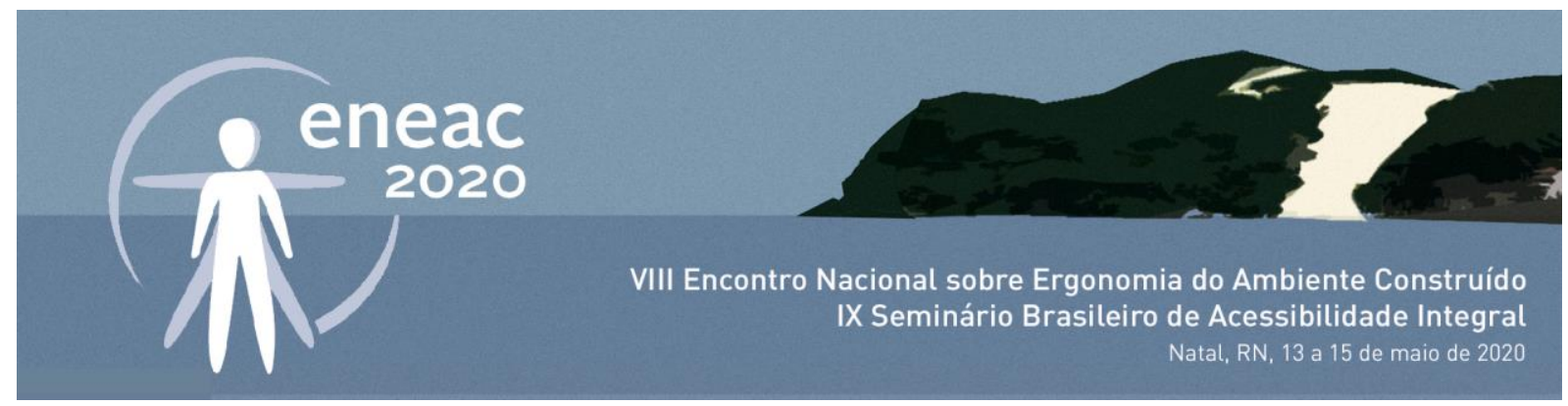

\section{Recomendações}

Considerando que o estudo foi realizado para fins de fornecer subsídios de diagnóstico a um projeto arquitetônico, as recomendações serão utilizadas como diretrizes projetuais. Como forma de promover melhoria das condições ergonômicas a partir da aplicação da metodologia de avaliação, sugere-se:

- Reforma para viabilizar melhor distribuição dos ambientes e ampliação da sala técnica, fazendo caber mesas maiores e com gavetas e armários suficientes para acomodar todos os pertences dos usuários, organizando a sala;

- Criação de uma circulação alternativa por fora da sala técnica, evitando a passagem de pessoas que não estejam trabalhando;

- Ajuste do layout, removendo obstáculos das circulações, tornando-as seguras e acessíveis;

- Nivelamento de pisos e adoção de rampas;

- Criação de espaços semi privativos para cada setor, com uso de painéis retráteis que permitam seu eventual fechamento sem ter que compartimentá-los completamente;

- Adoção de revestimentos e elementos que corrijam os problemas acústicos, absorvendo o som e diminuindo seu tempo de reverberação;

- Adoção de uma iluminação mais indireta e suave, com temperaturas mais quentes, e possibilidade de controle do usuário através de iluminações individuais e dimerizadas em cada posto de trabalho;

- Instalação de aparelhos de ar condicionado no forro, que não atinjam diretamente nenhum posto de trabalho;

- Embutir fiação elétrica, e colocar tomadas em cima de todas as mesas, evitando fios soltos no chão;

- Instalação de extintores e definição da rota de fuga;

- Uso de elementos de decoração e revestimentos que representem a identidade da marca.

\section{CONCLUSÃO}

A ergonomia aplicada aos ambientes construídos confere uma visão sistêmica onde elementos de diversas naturezas são observados e avaliados conjuntamente, tanto sob o foco dos aspectos técnicos, quanto preocupando-se com o olhar dos usuários sobre o espaço que ocupa. Não existe ergonomia se não se considera os fatores humanos.

Do estudo realizado depreende-se que o ambiente pesquisado se encontra em desacordo com algumas normas que regem o setor de espaços corporativos e não se mostra tão eficaz e confortável para os seus usuários, contrariando os princípios e preceitos da ergonomia. A partir da discussão dos problemas identificados, é possível concluir que os mesmos podem ser amenizados através de intervenções simples no interior do ambiente, no entanto só podem ser completamente corrigidos caso haja uma reforma que amplie o espaço da sala técnica. 


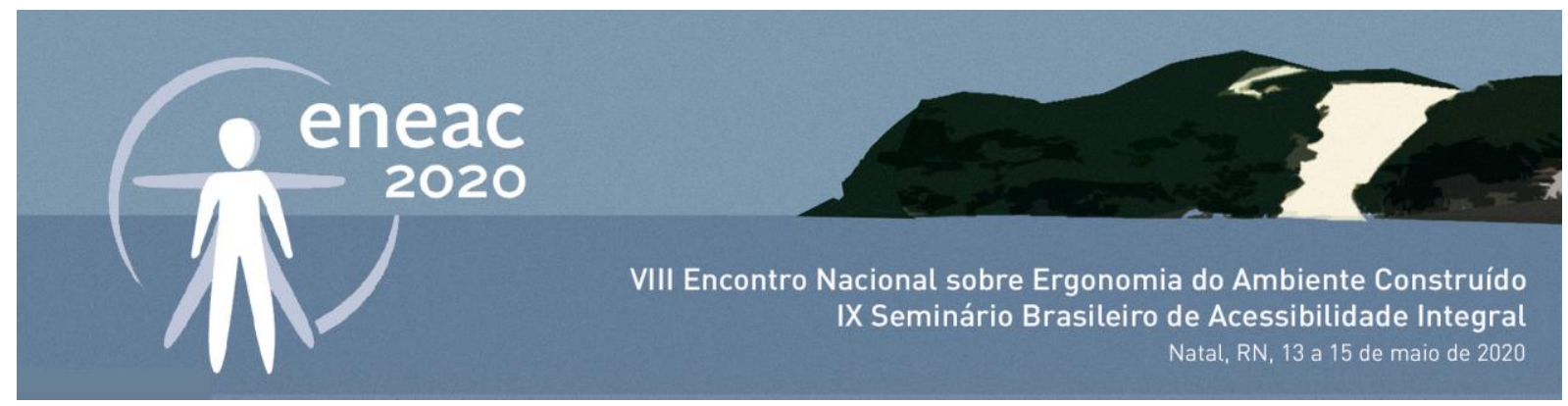

Existe, portanto, a demanda por uma intervenção arquitetônica baseada na ergonomia, e não somente uma reorganização do espaço, objetivando reduzir o risco de acidentes e de adoecimento dos funcionários, além de melhoria do conforto e bem estar, objetivos principais da proposição das melhorias indicadas, bem como aumentar o desempenho e a produtividade, beneficiando a empresa.

Desse modo, destaca-se a possibilidade de futuras pesquisas que abordem a execução do projeto pautado no levantamento ergonômico, percepção do público a respeito dos resultados gerados pela intervenção e também analisando o que os números revelam no que se refere ao desempenho da equipe.

\section{REFERÊNCIAS}

ABNT - Associação Brasileira de Normas Técnicas. NBR 10.152: níveis de ruído para conforto acústico. Rio de Janeiro: 1987.

ABNT - Associação Brasileira de Normas Técnicas. NBR 5413: iluminância de interiores. Rio de Janeiro: 1992.

ABNT - Associação Brasileira de Normas Técnicas. NBR 9050: acessibilidade a edificações, mobiliário, espaços e equipamentos urbanos.. Rio de Janeiro: 2015.

BRASIL. Ministério do Trabalho e Emprego. Norma Regulamentadora 17 - Ergonomia. Brasília: 2007.

BRASIL. Ministério do Trabalho e Emprego; Fundacentro. Norma de Higiene Ocupacional no11 - NHO 11: Avaliação de níveis de iluminamento em ambientes internos de trabalho. São Paulo: 2018

EKAMBI-SCHMIDT, J.. La percepción del hábitat. Barcelona: Editorial Gustavo Gili, S.A., 1974.

LINHARES, T. B.; BARBOSA, P. G.; TAKAMATSU, R. T.. Design de interiores como estratégia de promoção de inovação de startups. In: Projetica Revista cientifica de Design, v. 10, n. 3. Londrina, 2019.

MIRANDA, J. Q.; SANTOS JUNIOR, C. D.; DIAS, A. T.. A influência das variáveis ambientais e organizacionais no desempenho de startups. Revista de Empreendedorismo e Gestão de Pequenas Empresas, v. 5, n. 1, p.28-65, 2016

OLIVEIRA, A; SOARES, F; SOUZA, J; SALLES, L.H. Análise ergonômica do ambiente construído: estudo de uma panificadora na cidade do Recife.

PANERO, J.; ZELNIK, M. Dimensionamento humano para espaços interiores: um livro de consulta e referência para projetos. Barcelona: Editorial Gustavo Gili, 2002.

VARGAS; Heliana Comin. Da Escola de Chicago aos Edifícios Certificados: um olhar sobre a produção de escritórios na cidade de São Paulo - 1870-2010. In: Arquitetura e Mercado Imobiliario [S.I: s.n.]. Barueri: Manole; 2014

VILLAROUCO; Vilma (2007). O ambiente este adequado? In: Encontro Nacional de Ergonomia do Ambiente Construído, I e Seminário Brasileiro de Acessibilidade Integral, II. 2007, Recife, Anais... Recife: ENEAC, 2007. 